\title{
O direito à informação e o (ainda restrito) espaço cidadão no Jornalismo Popular impresso
}

\author{
Marise Baesso Tristão* \\ Christina Ferraz Musse***
}

\section{Resumo}

Este artigo objetiva mostrar como na era da informação o Jornalismo, muitas vezes, negligencia o estímulo ao exercício da cidadania, em especial o Jornalismo realizado pelos meios de Comunicação de grande circulação. Estes veículos, em geral, não priorizam temas que colaboram para a formação e o espírito crítico. A análise será focada nos jornais ditos populares, em especial o Super Notícia, periódico fundado em 2002, que se tornou o veículo impresso mais vendido no país, mas com circulação restrita aos municípios mineiros. A pertinência do assunto se dá já que os periódicos populares apresentam grande circulação e, muitas vezes, são a única fonte de leitura das chamadas classes subalternas. Para o estudo, utilizamos a Análise de Conteúdo. Entendemos que o espaço para o Jornalismo Comunitário é restrito, enquanto há ênfase em assuntos relacionados com o crime, os astros de TV e o futebol. No entanto, é preciso buscar este espaço e não apenas ficar no campo da crítica.

Palavras chave: Direitos. Informação. Cidadania. Mídia impressa. Jornalismo Popular.

\footnotetext{
* Jornalista, mestre pelo PPGCom da UFJF e doutoranda no Programa de Pós- Graduação em Comunicação, Curso de Comunicação, Universidade Federal Fluminense (UFF), Niterói-RJ, Brasil. E-mail: marisebaesso@hotmail.com.

** Professora doutora associada do Departamento de Televisão e Rádio e do PPGCOM, Faculdade de Comunicação da Universidade Federal de Juiz de Fora, Juiz de Fora-MG, Brasil. Vice-coordenadora do PPGCom da UFJF, coordenadora do Grupo de Pesquisa Comunicação, identidade e Cidadania.

E-mail:musse@terra.com.br.
} 


\section{The right to information and the (still limited) citizen's space in Journalism popular printed \\ Abstract}

This article aims to show how the information age journalism often neglects the stimulus to citizenship, especially journalism done by the media of general circulation. These vehicles generally do not prioritize issues that contribute to the formation and critical. The analysis will be focused in newspapers popular sayings, especially Super Notícia, journal founded in 2002, which became the best-selling vehicle in the country printed, but with restricted movement to municipalities miners. The relevance of the subject is given as the popular periodicals have great movement and are often the only source of reading calls subaltern classes. For the study, we used Content Analysis. We understand that the space for community journalism is restricted, while there is an emphasis on issues related to crime, TV stars and football. However, we must find this space and not just stay in the field of criticism.

Keywords: Rights. Information. Citizenship. Print media. Popular journalism.

\section{El derecho a la información y el espacio (aún limitado) en el periodismo ciudadano populares impreso}

\section{Resumen}

Este artículo tiene como objetivo mostrar cómo el periodismo era de la información a menudo deja de lado el estímulo a la ciudadanía, especialmente el periodismo hecho por los medios de difusión general. Estos vehículos generalmente no dan prioridad a cuestiones que contribuyen a la formación y crítica. El análisis se centrará en los periódicos dichos populares, en especial Super Notícia, revista fundada en 2002, que se convirtió en el vehículo más vendido en el país imprimió, pero con la restricción de movimientos de los municipios mineros. La relevancia del tema se da como las revistas populares tienen gran movimiento y son a menudo la única fuente de lectura de las llamadas clases subalternas. Para el estudio, se utilizó el análisis de contenido. Entendemos que el espacio para el periodismo comunitario está restringido, mientras que hay un énfasis en los temas relacionados con la delincuencia, estrellas de la televisión y el fútbol. Sin embargo, tenemos que encontrar ese espacio y no sólo que darse en el campo de la crítica.

Palabras clave: Derechos. Información. Ciudadanía. Los medios impresos. Periodismo popular.

\section{Introdução}

informação é um direito garantido por lei nas democracias
contemporâneas e deveria, cada vez mais, ter peso no sen-
tido de colaborar para a formação de cidadãos. Aliás, é por 
isso que carrega tamanha importância, por ser um bem precioso, que, no entanto, nem sempre é tratado como tal e nem sempre chega a todos de maneira irrestrita e democrática nas sociedades modernas. Não falamos da informação pura e simples, mas ressaltamos a informação que considera a perspectiva cidadã, que se preocupa com a formação de quem é informado e, principalmente, falamos da informação jornalística, nosso objeto de estudo. Gostaríamos de refletir, em especial, se a Comunicação voltada para a classe popular tem potencializado o direito à cidadania ou não.

De que maneira esta cidadania seria potencializada? Por meio da liberdade de expressão, direito humano fundamental para que haja democracia. Direito, aliás, que deveria ser tema bastante debatido a partir do ano de 2011, que foi denominado o "Ano da Liberdade de Imprensa", pela Sociedade Interamericana de Imprensa (SIP).

Neste artigo, mostraremos que a informação é um direito básico e fundamental neste espaço, chamado de Sociedade da Informação ou de outras diferentes maneiras, conforme denominado, por Gentilli (1995), como Sociedade de Consumo, Sociedade Programada, Sociedade de Massas, Neocapitalismo ou Capitalismo Democrático, mas que, muitas vezes, é negligenciada pela massa e manipulada por quem tem os veículos de Comunicação em mãos.

Apesar da importância da informação, confirmada pela denominação dada a esta era, e de haver cada vez mais suportes para que ela se propague, o que vemos ainda não é o predomínio dos veículos plurais que pretendem colaborar para o desenvolvimento de leitores e ouvintes críticos e que busquem a reflexão acima de tudo. Pelo contrário, o que existe, em sua maioria, são organizações que tratam a informação principalmente como mercadoria ao invés de priorizá-la como um importante instrumento de cidadania. Estamos falando de veículos de massa, mais especificamente de veículos tradicionais, como rádio, televisão e jornal impresso, que detêm o controle da informação. Veículos que, obviamente, precisam ter renda para se manter, mas que poderiam, principalmente em se falando daqueles que têm concessões públicas, caso das redes de televisão abertas e do rádio, dar voz ao cidadão e atrelar interesse público com interesse do público. Interesse 
público por defendermos que uma das funções do Jornalismo é o de prover o público de informações essenciais para o exercício e a construção dos direitos e deveres dos cidadãos. E interesse do público, levando-se em conta o seu universo e porque, afinal, ele é a razão de ser de todo veículo.

Ao longo dos últimos anos no país, jornais impressos denominados populares expandiram suas tiragens e chegaram ao topo da lista dos mais vendidos, reproduzindo o discurso da classe dominante ou trazendo conteúdos superficiais, espetaculares, policiais, de lazer ou esportivo sem que a classe realmente popular pudesse se ver no jornal ou participar dele. ${ }^{1}$ No entanto, estes veículos tiveram alguma evolução, principalmente na última década, e passaram a ter mais cuidado, por exemplo, no que tange ao texto e, principalmente, com relação à redução do tom agressivo antes adotado. Claro que ainda há o predomínio do espetáculo, com grande destaque para as reportagens que provocam emoções nos leitores e que quebram as fronteiras entre informação e entretenimento, mas já podemos ver, pelo menos em algumas colunas nestes jornais, a participação do "povo", ainda que restrita, com sugestões de matérias, perguntas, cartas, entre outras seções que buscam estimular a cidadania.

Neste momento de expansão desta mídia impressa, acreditamos ser importante verificar que caminho ela tem tomado no sentido de se aproximar da realidade de seu leitor e buscar melhorá-la. Pretendemos analisar neste artigo, especificamente, o jornal Super Notícia, o mais vendido hoje no país. Nossa intenção aqui é descobrir se há algum espaço nestes jornais para o despertar crítico e o espírito de cidadania. O periódico foi o escolhido para a análise por ter sido nosso objeto de estudo na dissertação de mestrado e se encaixar nas características do jornal popular,

\footnotetext{
${ }^{1}$ Consideramos os conceitos de Gramsci quando falamos de classe dominante e de popular (por ele chamada de subalternos). Este autor parte do conceito de sociedade civil para demonstrar que a classe dominante não mantém o poder apenas mediante a coerção, mas, também, por intermédio do consentimento (hegemonia). Para Gramsci, a hegemonia de uma classe significa a sua capacidade de subordinar intelectualmente as demais classes por meio da persuasão e da educação.
} 
que confere grande destaque ao tema violência e a outros, como variedades e esportes. $\mathrm{O}$ jornal não apresenta editorias de Economia e Política. Eventualmente, assuntos destas áreas aparecem em meio às notícias da editoria chamada Geral. Suas editorias são Opinião, Cidades, Geral, Variedades e Esportes.

Para este estudo, foi feita uma avaliação, usando princípios da Análise de Conteúdo, de Laurence Bardin. Para isso, foram verificados quatro exemplares, entre os dias 4 e 7 de janeiro de 2011. Durante estes dias, o número de páginas variou entre 24 e 28, dependendo da quantidade de anúncios publicitários. Foram verificados os exemplares como um todo, analisando os assuntos abordados.

\section{O reconhecimento do direito de informação}

Em seu livro A Era dos Direitos (1992), Norberto Bobbio afirma que não há direitos fundamentais por natureza. Segundo o autor, "o que parece fundamental numa época histórica e numa determinada civilização não é fundamental em outras épocas e outras culturas" (BOBBIO, 1992, p.18). Para este autor, os direitos humanos são direitos históricos que surgem na idade moderna a partir das lutas contra o Estado Absoluto. Ele defende que a Declaração Universal dos Direitos Humanos não é um documento fechado, mas um princípio norteador, cujo conteúdo precisa ser aperfeiçoado continuamente ao longo da história, já que ele foi escrito em um determinado momento, após a Segunda Guerra Mundial e com fortes influências da Revolução Francesa e da Revolução Russa. Soma-se a isso o fato de que os direitos são traçados para atender a determinados interesses do grupo que os cria. Por exemplo, influenciada pelo pensamento burguês, que delineou a Revolução Francesa, a Declaração dos Direitos Humanos considera a propriedade como um direito natural e imprescindível, algo que seria questionável pelos socialistas.

Assim, estes períodos da história foram decisivos para a definição de muitos dos princípios que ali estão declarados. É preciso, porém, reconhecer a importância deste passo para toda a humanidade e para o despertar da consciência dos direitos, além da evolução da imagem do homem de súdito para cidadão. No entanto, 
a partir da declaração, é necessário haver adequações às novas demandas das sociedades e à evolução natural. Com isso, foram sendo criadas e devem continuar sendo produzidas declarações que defendam os direitos das crianças, das mulheres, das minorias, direitos contra a discriminação racial e de todas as demandas que surjam, no sentido de construir sociedades mais justas, igualitárias e participativas. Sem esquecer o que Bobbio ressalta que, ao ser criado um novo direito, outro acaba sendo suprimido:

\begin{abstract}
Não se pode afirmar um novo direito em favor de uma categoria de pessoas sem suprimir algum velho direito, do qual se beneficiavam outras categorias de pessoas: o reconhecimento do direito de não ser escravizado implica a eliminação do direito de possuir escravo; o reconhecimento do direito de não ser torturado implica a supressão do direito de torturar (BOBBIO, 1992, p.23).
\end{abstract}

Entre as novas demandas da sociedade atual, podemos destacar as que estão sendo criadas junto com a frenética evolução da tecnologia, especialmente da internet. São demandas que exigem o direito à inclusão digital. Direito que é realidade nas nações mais abastadas do mundo e ainda uma utopia nos países mais miseráveis, como muitos da América Central e da África. Situação esta que levou a uma constatação pela ONU. "A própria Organização das Nações Unidas (ONU) estabeleceu o atraso digital como uma das quatro grandes mazelas da atualidade, ao lado da fome, do desemprego e do analfabetismo" (CASTRO, 2006, p.53).

No Brasil, as tecnologias da Comunicação ainda estão longe de ser totalmente democratizadas, e uma política para que estes suportes tenham seus custos barateados faz parte da luta pela inclusão digital, travada em várias frentes da sociedade. O quadro tem evoluído, mas ainda há muito o que fazer. Segundo a Pesquisa Nacional de Amostras por Domicílio (PNAD) ${ }^{2}$, divulgada

\footnotetext{
${ }^{2}$ Pesquisa feita pelo Instituto Brasileiro de Geografia e Estatística (IBGE) em uma amostra de domicílios brasileiros e que, por ter propósitos múltiplos, investiga diversas características socioeconômicas. Exemplos de características investigadas: população, educação, trabalho, rendimento, habitação, previdência, migração, fecundidade, nupcialidade, saúde, nutrição etc.
} 
em 2010, o número de usuários de internet no Brasil cresceu 12 milhões entre 2008 e 2009. Mesmo assim, em 2009, a internet era acessível a menos da metade da população: 41,7\%. Ou seja, a maioria, ainda não está plugada na rede. E, entre os que estão, a maior parte reside nas regiões Sudeste e Sul do país.

Recorremos a Bobbio novamente para lembrar que, se, em outras épocas, o direito à informação era considerado secundário ou nem era considerado como tal, hoje é essencial e quem detém a informação ou é propagadora dela ou tem o poder em mãos. $\mathrm{O}$ direito à informação pode ser considerado um dos bens mais valiosos da era contemporânea. Mas como este direito tem sido desfrutado numa sociedade como a brasileira? E mais, os cidadãos têm ciência da importância de quem domina aqueles que são os maiores propagadores da informação: os meios de Comunicação de massa?

Ora o direito à informação se refere à liberdade de ser informado e também de informar, ou seja, de se expressar. Gentilli diz que o direito à informação é um direito-meio porque vai possibilitar que outro direito se concretize. Ele recorre à política eleitoral para dar o exemplo:

Se por exemplo todos os cidadãos não forem informados sobre todas as alternativas em disputa numa determinada eleição, esta eleição passa a contar com um vício de origem, que, embora não a desqualifique como antidemocrática, torna-a menos democrática (GENTILLI, 1995, p.145).

Não só Gentilli, mas Dallari (2002) ressalta esta questão do direito à informação: "quando alguém, não sabe que tem um direito ou dispõe apenas de informações vagas e imprecisas sobre ele, é pouco provável que venha a tomar alguma atitude em defesa desse direito ou que vise à sua aplicação prática (DALLARI, 2002, p.69)”.

No caso do acesso à informação e à Comunicação, é preciso buscar princípios e conceitos relativos à cidadania e à inclusão social. É preciso fazer valer, transformando em políticas públicas, as diretrizes defendidas em fóruns, conferências e seminários, como o encontro que terminou com a confecção da "Carta de São Bernardo", em novembro de 2005, no município de São Bernardo do Campo (SP), que reuniu pesquisadores e ativistas de Comunicação 
social de todo o país. Uma das propostas aprovadas e direcionada aos conglomerados de Comunicação diz o seguinte:

Convidamos as empresas de mídia para ampliar sua participação social, através de ações e conteúdos dentro dos princípios da mídia cidadã; valorizar e qualificar seus profissionais nos princípios de responsabilidade social; inserir conteúdos locais/regionais, respeitando e garantindo a diversidade cultural; estimular a presença de minorias e difundir os direitos humanos nos conteúdos midiáticos, preservando, assim, as identidades e peculiaridades, locais ou regionais (CARTA DE SÃO BERNARDO, 2006, p.244).

Neste sentido, a crítica se dá à concentração do poder e do maior acesso nas mãos dos que detêm o maior conhecimento e não das minorias. Cabe aqui defender a criação de políticas públicas para que seja possível facilitar a participação ativa de cada indivíduo nesta sociedade da informação. Afinal Peruzzo (2004, p.77) diz que "o direito à Comunicação na sociedade contemporânea inclui o direito ao acesso de poder comunicar". Somente assim, o cidadão assumiria um papel ativo no processo de Comunicação.

Para muitos autores, entre eles Gentilli, o Jornalismo é mesmo indispensável para o exercício da cidadania nas sociedades modernas. "A necessidade social de informação produz a necessidade do Jornalismo" (GENTILLI, 1995, p. 24). Ainda que ressalvas sejam feitas, diante dos monopólios de Comunicação, é o Jornalismo o fator primeiro que permite o acesso à informação para uma massa. Não importa se o veículo usado é o jornal impresso, o rádio, a televisão ou outros meios digitais. Mas a forma como o Jornalismo tradicional vem sendo feito e os enquadramentos utilizados são fatores preponderantes.

\section{Jornalismo "Popular"}

O Jornalismo Popular do qual falamos é aquele que se refere a um grupo de novos jornais, que se autodenomina "popular". São veículos impressos destinados, prioritariamente, às classes subalternas - usando o termo de Gramsci. São editados por grupos jornalísticos consolidados no país, que não possuem equivalência 
com jornais populares, comunitários, alternativos ou sindicais, nem estão no mesmo escopo teórico dos mesmos.

Nestes jornais ditos populares, em geral, destacam-se entre os critérios de noticiabilidade o fait divers, o entretenimento e o escândalo. Outros critérios vêm ganhando espaço, como a prestação de serviço, no entanto, ainda são menos valorizados, com algumas exceções. Desta forma, ao invés de ter conteúdos midiáticos que favoreçam a crítica e a formação cidadã, estes assuntos que recheiam esta mídia popular acabam colaborando para o reforço de estereótipos.

Da mesma forma, ao ter ao alcance de suas mãos (e de seu bolso) jornais e programas da televisão aberta que transformam mortes, crimes e sexo em notícia e em espetáculo, o indivíduo se convence de que esse é o seu lugar dentro da lógica informativa (e também social) e assume o papel para si. $\mathrm{O}$ argumento favorável a esse tipo de Jornalismo pode afirmar que, de fato, as pessoas se interessam pela sua realidade, permeada de mortes, crimes e sexo: 'ao valorizar a notícia que traduz um fato violento, o jornal sensacionalista está apenas atendendo a um desejo específico de seu público' (ANGRIMANI, 1995, p.57).

Franscislene Paula (2009) critica o fato de esta ser a única opção possível para essas pessoas. A autora lembra ainda que, pelo senso comum, acredita-se que, no Brasil, as pessoas que fazem parte das classes mais pobres não teriam capacidade intelectual para ter acesso ou refletir sobre assuntos mais "sérios", os temas das chamadas editorias mais pesadas, como Política e Economia.

Recorrer ao pensamento de Paulo Freire aqui é essencial quando o educador lembra a forma como o analfabetismo é tratado no Brasil: “[...] como a manifestação da 'incapacidade' do povo, de sua 'pouca inteligência', de sua 'proverbial preguiça' (FREIRE, 1978, p.13)”. O educador adverte que o 'analfabetismo não é um problema estritamente linguístico, nem exclusivamente pedagógico, metodológico, mas político, como a alfabetização, através da qual se pretende superá-lo" (FREIRE, 1978, p.16). Lembra ainda que os trabalhadores mais simples não são como "vasilhas vazias", nas quais os "especialistas" vão depositando conhecimento. Cada um tem sua sabedoria, que deveria ser considerada na educação 
de adultos e aguçada, no sentido de desenvolver um pensamento crítico no trabalhador.

Mas nos jornais ditos populares, que têm apresentado crescimento em várias regiões do Brasil, dificilmente se veem conteúdos que estimulem este pensamento. Justamente estes jornais que chegam às mãos de pessoas que antes não tinham o hábito de leitura de uma mídia impressa e poderiam ser o grande filão no sentido de formação da cidadania. Em geral também são reduzidos os assuntos regionais e comunitários nestes impressos. Os populares viraram veículos com circulações recordes, preços acessíveis e que, em muitos casos, apresentam venda casada, no sentido de oferecer não só a informação, mas brindes.

Jornalismo voltado para uma camada da população que, segundo o imaginário construído em anos de história, está em busca de sensações e divertimento, seja qual for o assunto tratado. Por esse imaginário difundido, indivíduos das classes $\mathrm{C}$ e $\mathrm{D}$ têm por opção jornais que primam por uma linguagem popular (com uso de gírias e palavras), fotos de mulheres seminuas nas capas, que também têm pequenas chamadas, muitas vezes com duplo sentido, das notícias do dia (PAULA, 2009, p.38).

Segundo o IVC (Instituto Verificador de Circulação) ${ }^{3}$ de março de 2010, dos cinco primeiros jornais mais vendidos do país, os dois primeiros são populares. O primeiro é o Super Notícia, com 303.269 exemplares diários. O segundo é o Extra, do Rio de Janeiro, com 302.697. Somente em terceiro lugar aparece a Folha de S.Paulo, que foi o líder por vários anos, com 292.626 exemplares vendidos diariamente. Em seguida, com o quarto lugar, está $O$ Globo, com 251.525, e, em quinto, o jornal O Estado de S.Paulo, com 230.051 exemplares. Outros dois jornais populares ficam entre os dez mais lidos do país: o Meia Hora, do Rio, com 159.766, e o Aqui, de Minas, com 137.612.

\footnotetext{
${ }^{3}$ O Instituto Verificador de Circulação (IVC) é responsável pela auditoria de circulação dos principais jornais e revistas do Brasil e, por consequência, a principal referência neste segmento, além da auditoria de web sites. http://www. ivcbrasil.org.br .
} 
Entre os fatores para este crescimento estão os preços, como já dissemos. O valor do exemplar do Super Notícia, por exemplo, é de $\mathrm{R} \$ 0,25$. Outra característica preocupante destes jornais populares com altas tiragens, no que diz respeito aos conglomerados que detêm a informação, é que todos pertencem a grupos proprietários de jornais de referência. No caso do Super Notícia, ele pertence ao Grupo Sempre, cujo proprietário é o ex-deputado federal pelo PSDB Vitório Mediolli, também dono de um conglomerado de meios de Comunicação em Minas, entre eles, o jornal O Tempo. Já o popular Aqui é ligado ao mesmo grupo de $O$ Estado de Minas, ambos dos Diários Associados, um dos mais tradicionais do Estado. No Rio de Janeiro, a situação se repete: o popular Extra é do Infoglobo, mesmo grupo de O Globo, enquanto o Meia Hora está ligado ao Dia. Portanto, são jornais criados para atender, acima de tudo, os interesses da corporação, já que há uma crise financeira mundial na mídia impressa tradicional, um crescimento do poder econômico da classe C (para a qual o modelo popular é voltado prioritariamente) e uma migração de muitos leitores para a internet.

As evoluções neste universo, que antes era formado apenas pelos veículos que "espremiam e saíam sangue", devem ser mencionadas. Para Márcia Franz Amaral (2006), as mudanças devem ser reconhecidas:

[...] é necessário reconhecer também nessas publicações outras características e méritos, como a articulação de demandas sociais, dinâmicas culturais, além da amplificação da fala dos setores populares (AMARAL, 2006), colocados, tradicionalmente, à margem da sociedade e que nos jornais populares ganham posição de destaque. Compreender e reconhecer os jornais populares apenas pela via do sensacionalismo é adotar um olhar restrito e empobrecedor (NORONHA, 2007, p.22).

Porém estas mudanças, ainda são tímidas e continuam sem aprofundamento nos temas cidadãos. No entanto, como são mudanças muito recentes, ainda carecem de estudos mais aprofundados em nosso país. Por enquanto, a receita para cativar os leitores é unir a prestação de serviços, o noticiário da cidade, ainda que restrito, o apelo sexual, sempre com mulheres seminuas na capa, 
fofocas do mundo das celebridades, além da permanência das notícias sobre crimes, que continuam sendo o carro chefe. Dentro da categoria, um dos jornais que tem buscado a aproximação com o leitor é o Extra, do Rio. Apesar de não ser nosso objeto de estudo, é importante mencionar aqui atitudes desta mídia no sentido de desenvolver o espírito crítico de seu leitor.

No Rio de Janeiro, um boneco de pano de tamanho humano faz sucesso entre os leitores do Extra. É o "João Buracão". Confeccionado por um borracheiro carioca para chamar a atenção para um buraco que, apesar dos constantes pedidos, não era tapado pelas autoridades, o boneco foi descoberto por um repórter do jornal e logo foi "adotado" pelo Extra. Agora, "João Buracão" é disputado por moradores de ruas esburacadas. Problemas que levavam meses para serem resolvidos desaparecem em questão de dias. O leitor denuncia, "João Buracão" vai ao local, o jornal publica a notícia e logo depois o buraco é tapado. Uma dor de cabeça para prefeitos e uma ferramenta para os leitores. Recentemente, O Dia lançou o "Repórter Lampião", um concorrente para o boneco. Leitores levam um lampião para ruas com recorrentes problemas de iluminação pública para forçar as autoridades a tomar providências (DINES, 2009).

Ao se colocar como porta voz de uma população, que busca um direito social, o jornal cumpre o seu papel de pressionar as instituições públicas para atingir um direito do povo. Em geral, no Jornalismo Popular, outros temas, como direito do consumidor, também avançam, mas faltam ainda assuntos importantes que façam referências aos princípios considerados essenciais para a cidadania, como a política, como participação por meio de protestos e atuação dos representantes eleitos, e a liberdade individual garantida pela atenção a direitos fundamentais, como direitos sociais à educação, à saúde, ao trabalho e à segurança.

\section{Jornalismo Comunitário}

José Marques de Melo realizou várias pesquisas e também estimulou outros pesquisadores a estudar este tipo de mídia, que era chamada de nanica, nos anos de 1960-1970, para designar os tablóides com notícias populares. Na virada democrática do país, 
nos anos de 1980, ele voltou "a sugerir que as novas gerações de pesquisadores da área explorassem a mídia cultivada pelas classes subalternas" (MELO, 2006, p.23). A intenção do autor era verificar se, ao invés de estigmatizar esta mídia como espaço de alienação política, fosse testada a hipótese de resistência possível dos excluídos pela sociedade de consumo. No entanto, Melo teve robustecida "a tese de que a imprensa comunitária brasileira, com raras exceções, pauta-se por critérios e motivações externos às comunidades a que servem." (MELO, 2006, p.24). Por outro lado, este mesmo autor ressalta que os veículos considerados comunitários vêm ganhando espaço no país, com as rádios populares, o jornal de interior e o ciberespaço. Somam-se a estes veículos, outras importantes iniciativas no sentido de desenvolver temas cidadãos na mídia em geral hoje:

A criação de agências de notícias especializadas em causas sociais (Agência de Notícias dos Direitos da Infância - Andi, por exemplo), os suplementos de prestação de contas acerca da responsabilidade social de grandes veículos da imprensa, as iniciativas de empresas privadas em estimular, através de prêmios, as pautas vinculadas a direitos sociais e civis, e o contra-agendamento possibilitado pelos factoides produzidos por instituições ligadas ao Terceiro Setor. São instrumentos que têm obtido resultados concretos, colaborando para maior visibilidade de temas ligados ao interesse público e à ampliação do direito à informação como ferramenta para a construção da cidadania (PREVEDELLO, 2008, p.54-55).

Diante da realidade brasileira, na qual um número reduzido de grandes conglomerados tem o "direito" de ser dono das maiores redes de Comunicação, é mister ressaltar a importância de haver projetos, como estes mencionados, que busquem maior espaço e a criação de leis que protejam e defendam o direito dos chamados veículos alternativos, que comunguem com a defesa da igualdade e dos direitos dos grupos historicamente excluídos. Mais que isso, veículos cuja programação seja feita por cidadãos comuns e não por especialistas apenas. Estes grupos, geralmente, não são retratados da melhor maneira ou não são sequer retratados em muitos veículos, até mesmo aqueles que se dizem populares. Mas não basta criticar. "Quanto a isso, Peruzzo avalia que criticar a mani- 
pulação das grandes redes de rádio, televisão e impressos é pouco. É preciso ocupar espaços e se organizar para descentralização e reordenamento dos meios" (LAHNI, 2010, p.169).

A pressão por leis e por maior celeridade nos processos que legalizam, por exemplo, as rádios comunitárias, também necessita ser feita por nossos representantes políticos e por movimentos sociais, já que, diante da morosidade destes processos, muitas rádios passam anos na ilegalidade. Lilian Bahia lembra que, em 2005, havia dez mil pedidos de abertura de emissoras aguardando despacho no Ministério das Comunicações, que deveria liberar apenas 1,5 mil por ano. Assim, cerca de 15 mil rádios funcionavam no Brasil sem autorização naquele ano (BAHIA, 2006, p.118). Até hoje, sabemos que não há celeridade para resolver e legalizar rádios, diante do exemplo da Mega FM, em Juiz de Fora. A rádio foi fechada e, apesar de toda a documentação legal que a define como autêntica comunitária, continua sem abrir os microfones para moradores do Bairro Santa Cândida e regiões vizinhas.

\section{O Super Notícia}

Em que lugar se encaixa o jornal estudado, o Super Notícia? Para compreender o fenômeno deste jornal é necessário que se entenda a situação do veículo, assim como as perspectivas do sensacionalismo, da espetacularização e da estereotipagem, que ainda são características predominantes nestes periódicos populares. Conforme Noronha (2007, p.40), a linguagem do Super é direta e objetiva, e o jornal apresenta, sobretudo, notas no lugar de matérias. "Podemos considerar que, em sua maioria, as notícias do Super se encerram no lead, ou seja, no ponto principal do acontecimento, sem discorrer muito sobre os detalhes. Nesse aspecto, assemelham-se às notícias da internet, curtas, com o conteúdo sucinto. Em seu estudo, Noronha percebeu que, mesmo na matéria de capa, nota-se uma superficialidade na abordagem dos acontecimentos. Apesar disso, é um jornal que

Ao contrário dos antigos jornais populares e sensacionalistas, como Notícias Populares, por exemplo, Super Notícia não utiliza termos chulos ou 
baixos, embora aborde com frequência assuntos sangrentos e polêmicos. Seria improvável encontrar, no Super, manchetes como "Aumento de merda na poupança", "Bicha põe rosquinha no seguro", "Broxa torra o pênis na tomada", já publicadas no extinto Notícias Populares. Entretanto, nem tão ao céu, nem tão à terra, nas manchetes do Super Notícia há sempre doses de ambiguidade, polêmica, comicidade ou curiosidade, com destaque para as manchetes da capa (NORONHA, 2007, p.41).

O veículo tabloide tem hoje o maior número de leitores diários no país. O jornal, com sede em Contagem, foi criado em $1^{\mathrm{o}}$ de maio de 2002. As vendas dos mais de 300 mil exemplares por dia são realizadas principalmente na região metropolitana da capital mineiras, mas o jornal tem leitores na maioria das cidades mineiras.

Em agosto de 2007, o Super, atualmente vendido a $\mathrm{R} \$ 0,25$, alcançou o primeiro lugar no ranking dos jornais de maior circulação geral do país, com uma média de 300.322 exemplares vendidos por dia, de acordo com Instituto Verificador de Circulação (IVC). Essa classificação, além de vendas avulsas em bancas e por ambulantes, também contabiliza as assinaturas. Com isso, o Super Notícia está à frente de tradicionais jornais de circulação nacional, como Folha de S. Paulo ( $2^{\circ}$ do ranking), O Globo (3ํ) e O Estado de S. Paulo (5). Desde julho de 2007, no entanto, o Super Notícia já havia assumido a primeira colocação no ranking de vendas avulsas, superando o Extra, do Rio de Janeiro, ( $2^{\circ}$ em vendas avulsas, $4^{\circ}$ em circulação geral) (NORONHA, 2007, p.25).

Durante o período pesquisado, notou-se um silêncio no que diz respeito a temas como saúde pública, educação, política como participação do cidadão por meio de protestos e da atuação dos representantes eleitos e de matérias sobre a segurança como direito. Também foi verificada como se dá a participação direta do cidadão.

No jornal do dia 4 de janeiro, do total de páginas, além da capa e Opinião, cinco eram da editoria Cidades (com temas policiais e tragédias), duas eram da editoria Geral, meia página da coluna "Por onde anda", seis de Variedades, uma de Emprego e seis de Esportes, sendo apenas uma das matérias referente ao nadador Cesar Cielo, e as demais sobre futebol. No jornal do dia 5 de janeiro, o jornal trouxe cinco páginas de Cidades, duas de Geral, sete de Variedades, duas sobre Carros e Motos e cinco páginas de 
Esporte. No dia 6 de janeiro, foram cinco páginas de Cidades, meia página da coluna Por onde anda, uma página de Geral, sete páginas de Variedades e cinco de Esportes. No último dia analisado, 7 de janeiro, foram cinco páginas de Cidades, uma de Geral, sete de Variedades e cinco de Esportes. Destaque neste dia, que é uma sexta-feira, para a editoria Variedades, que traz uma página somente de programação de lazer para o fim de semana com preços populares ou programas gratuitos, de música e teatro, por exemplo, somente em Belo Horizonte.

Em um primeiro momento, é importante destacar que o jornal é sustentado por: notícias policiais/tragédias, informações sobre artistas de televisão, horóscopo e palavras cruzadas e as notícias sobre futebol. No caso da editoria Cidades, quase 100\% das notícias são de Belo Horizonte e de outras cidades mineiras, com assuntos como crimes violentos em geral, mortes, acidentes de trânsito em ruas e estradas e algum fait-divers, como o do estudante de medicina da UFMG que fugiu com o dinheiro dos formandos, divulgada no dia 4 de janeiro ("Calote acaba com baile de formatura"), ou o fato de um médico ter sido negligente em uma cirurgia ("Médico esquece pinça em barriga de paciente"), publicada em 5 de janeiro. Citamos estes dois assuntos apenas para ilustrar, já que nossa atenção ao analisar estes exemplares foi identificar como o leitor, no caso a classe popular, aparece no jornal ou pode se pronunciar.

Apesar de o jornal não ter notícias diretamente relacionadas às decisões políticas e econômicas do país, algumas reportagens chamam atenção nos dias verificados. A política é tratada não pelos temas, mas pelas personalidades. Há assuntos como a morte do senador mineiro Eliseu Rezende, no dia 4 de janeiro, o tratamento de saúde do ex-vice presidente da República, José Alencar, que, segundo o jornal do dia 4 de janeiro, voltaria a fazer quimioterapia, e ainda uma série de ameaças que estariam sendo feitas pelo Twitter à presidenta Dilma Rousseff. Ou seja, os temas políticos, as discussões, os projetos e os assuntos de um novo governo não são sequer mencionados, apenas as pessoas.

Nos quatro dias analisados, identificamos que o leitor se pronuncia diariamente na coluna Alô redação, que ocupa a metade 
da página 2 (Opinião), com uma média de três a quatro cartas escolhidas pela redação com assuntos relacionados a matérias do jornal, problemas sobre mendicância nas ruas, elogios ao periódico ou para desejar um feliz 2011 para os demais leitores e para os times de futebol. É um espaço aparentemente democrático, no qual os leitores apresentam suas opiniões e tentam dialogar com leitores cujas cartas já foram publicadas.

Além deste espaço, às terças e quintas-feiras, o jornal possui uma coluna, de meia página, na qual o próprio leitor escreve. Este espaço, que poderia ser destinado a reclamações, queixas e uma oportunidade para o leitor dar opiniões em geral, falar da sua comunidade etc., restringe-se a quatro assuntos. $O$ leitor pode escrever por meio de carta ou e-mail apenas para "procurar alguém que saiu e não voltou, um amigo que não vê há tempos, o seu carro roubado e documentos perdidos". A coluna recebe o nome de Por onde anda e teve 13 participações em 4 de janeiro e outras 13 no dia 6 de janeiro.

Segundo Márcia Franz Amaral (2006), a existência de uma editoria como esta é uma tendência nestes jornais ditos populares. Neste espaço, o jornal quer deixar claro a importância da opinião de seus leitores. No entanto, há veículos, como o Meia Hora, do Rio de Janeiro, por exemplo, no qual esta participação é mais variada, na coluna Voz do Povo. Conforme Francislene Pereira de Paula (2009, p.84), neste espaço do Meia Hora o leitor pode:

Ache o amor de sua vida, procure pessoas desaparecidas, aumente seus conhecimentos, cobre dos políticos, faça valer os seus direitos de cidadão! Escreva, reclame, participe!". Portanto, neste jornal, a questão "cidadania" é tratada de forma mais explícita: "[...] a 'Voz do Povo' procura fazer a ponte entre a sociedade e o governo, além de mobilizar a própria sociedade na resolução de problemas.

Também durante os quatro dias analisados, apenas na terça-feira, dia 4 de janeiro, foi publicada a coluna Emprego, que difere, a nosso ver, do tipo de conteúdo geral do jornal, que fica entre a divulgação do crime, do grotesco e do lazer (televisão e futebol). A coluna se encaixaria em um tipo de Jornalismo de serviço, com 
dicas de empregos e indicações de cursos de informática, corte e costura, entre outros.

Outro ponto a ser destacado é o estímulo do leitor como consumidor e não como cidadão. Diariamente, o jornal busca alavancar suas vendas com promoções. Durante os dias analisados, na capa havia uma promoção de juntar três selos do jornal, que seriam recortados, mais a quantia de $\mathrm{R} \$ 15,90$, para que o leitor/ consumidor levasse para casa uma prancha de cabelo. Em fundo de cor rosa, a propaganda é uma clara tentativa de atrair o segmento feminino para a leitura do jornal.

Avaliamos, portanto, que, em geral, o conteúdo apresentado pelo Super Notícia não prioriza o leitor como cidadão. Apesar de se enquadrar no chamado novo Jornalismo Popular, que não se restringe, por exemplo, apenas aos escândalos, seus espaços destinados ao leitor são muito restritos.

\section{Considerações finais}

O Jornalismo impresso dito popular, mas não comunitário, prima mais pela Comunicação como entretenimento e não como eduComunicação. Isto pode ser confirmado pelo pouco espaço aberto para o leitor no Super Notícia, se comparado com os assuntos que ganham as páginas, que não refletem o dia a dia das comunidades leitoras, já que a maior parte do jornal divide-se entre o crime e os astros de TV e do futebol. Acreditamos então que, em geral, esta leitura é alienante e não estimula a participação. Leitura que faz as pessoas saírem de sua realidade e pensarem na rotina do astro do futebol ou da novela ou sentir pena (ou outro tipo de emoção) daquele e daquela que foram alvos de crimes bárbaros, aumentando ainda a sensação de insegurança nas cidades. Em geral, são matérias que buscam uma espetacularização da realidade, ficando distantes do comunitário, que seria a aproximação com a vida concreta das populações. É uma pena que assim seja, já que estudos anteriores, como o de Noronha, mostram que o Super atinge pontos de Minas que antes tinham baixíssimo hábito de leitura de jornais. 
Se há avanço no sentido do texto e das manchetes que são menos agressivas e não trazem gírias ou palavrões, redução das imagens chocantes e ainda redução do fator sensacionalista, que mistura sangue, humor e sexo, ainda há muito a caminhar no conteúdo e nos temas, principalmente no que diz respeito à erotização da mulher. A concepção ainda é de um público leitor machista, já que, além de a mulher ter sua imagem explorada na capa do jornal, no sentido de aumentar a venda no segmento masculino, o jornal, ao tentar atrair as leitoras, não aposta em conteúdo, mas apenas em promoções. Como foi dito, durante os dias analisados, a promoção era "Leve na bolsa sua prancha de cabelo por apenas 3 selos e R \$15,90".

Portanto, o Jornalismo chamado Popular ainda está longe daquele Comunitário. Mas não bastam críticas, como já dissemos, é preciso conscientizar sim, a classe profissional e os conglomerados, de que as classes subalternas, principal leitora deste Jornalismo, são formadas por cidadãos, que não são apenas "vasilhas vazias", mas pessoas com direitos e que merecem refletir sobre eles.

\section{Referências}

AMARAL, Márcia F. Jornalismo popular. São Paulo: Contexto, 2006.

ANGRIMANI SOBRINHO, Danilo. Espreme que sai sangue. Um estudo do sensacionalismo na imprensa. São Paulo: Summus, 1995.

BAHIA, Lilian Claret M.. Rádios comunitárias. In: MELO, J.M.de; GOBBI, M.C.; SATHLER, L. (Orgs.) Mídia cidadã: utopia brasileira. São Bernardo do Campo: Universidade Metodista de São Paulo, 2006. p.113-126.

BARDIN, Laurence. Análise de conteúdo. Lisboa: Edições 70, 1979.

BOBBIO, Norberto. A era dos direitos. Rio de Janeiro: Campus, 1992.

CASTRO, Cosette. O sistema nacional no espaço global. In: MELO, J.M.de; GOBBI, M.C.; SATHLER, L. (Orgs.) Mídia cidadã: utopia brasileira. São Bernardo do Campo: Universidade Metodista de São Paulo, 2006. p.49-64.

COSTA, António Firmino da. Identidades culturais urbanas em época de globalização. Revista Brasileira de Ciências Sociais, São Paulo, Anpocs, v.17, n.48, p.15-30, fev. 2002. 
DALLARI, Dalmo de Abreu. Direitos humanos e cidadania. São Paulo: Moderna, 2002.

DINES, Alberto. Jornais populares. Resumo do programa Observatório da Imprensa. 15 abr. 2009. Disponível em:

http://www.tvbrasil.org.br/observatoriodaimprensa/cme/090414_resumo_498. htm. Acesso em: 8 jan. 2011.

FREIRE, Paulo. Ação cultural para a liberdade - e outros escritos. 3.ed. Rio de Janeiro: Paz e Terra, 1978.

FREITAS, Amílcar Cardoso Vilaça de. A imprensa carioca e a demanda por ordem no século XXI: estresse para todos?. 2009. 123f. Dissertação (Mestrado em Sociologia e Direito) - Universidade Federal Fluminense, Niterói.

GENTILLI, Victor. Democracia de massas: cidadania e informação. 1995. Dissertação (Mestrado em Comunicação) - Universidade de São Paulo.

GITLIN, Todd. The whole world is watching: mass media in the making and unmaking of thenew left. Berkeley: University of California Press, 1980. p.6-50.

GOFFMAN, Erving. A representação do eu na vida cotidiana. Petrópolis: Vozes, 1989.

GRAMSCI, Antonio. Concepção dialética da história. 2.ed. Rio de Janeiro. Civilização Brasileira. 1978.

LAHNI, Cláudia R.. Pesquisa participante e cidadania: conceitos e reflexões para o estudo de uma rádio comunitária autêntica. In: COUTINHO, Iluska; ALVARENGA, Nilson A.(Orgs.) Identidade e tecnocultura: a Comunicação em questão. Rio de Janeiro: Mauad X, 2010. p. 161-177.

MELO, José Marques de, GOBBI, Maria Cristina, SATHLER, Luciano (Org.) Mídia cidadã: utopia brasileira. São Bernardo do Campo: Universidade Metodista de São Paulo, 2006.

MORETZSOHN, Sylvia. O caso Tim Lopes: o mito da "mídia cidadã". Discursos Sediciosos: Revista Instituto Carioca de Criminologia, Rio de Janeiro, Revan, n.12, p.291-317, 2002.

PAULA, Francislene Pereira de. Jornalismo popular: sensações a serviço da afirmação de uma identidade nacional. 2009. (Monografia em Comunicação Social) Universidade Federal de Juiz de Fora, Juiz de Fora. 
PERUZZO, Cicília M.Krohling. Direito à Comunicação comunitária, participação popular e cidadania. In: OLIVEIRA, Maria José da C. (Org.). Comunicação pública. Campinas: Alínea, 2004. p.49-79.

PREVEDELLO, Carine Felkl. Representações no jornalismo popular: a cidadania no discurso do Extra (RJ). 2008. Dissertação (Mestrado em Comunicação Social). Universidade Federal de Santa Maria Santa Maria.

NORONHA, Flávia L.Ayer. Super fenômeno - o sucesso de um jornal popular mineiro. 2007. 108 f. Monografia (Graduação em Comunicação Social) - Universidade Federal de Minas Gerais, Belo Horizonte.

Recebido: 15/06/2012

Aceito: 20/01/2013 